\title{
Current management of diabetes mellitus and future directions in care
}

\author{
Sudesna Chatterjee, Melanie J Davies
}

Leicester Diabetes Research Centre, University of Leicester, Leicester General Hospital, Leicester, UK

\section{Correspondence to} Dr Sudesna Chatterjee, Leicester Diabetes Research Centre, University of Leicester, Leicester General Hospital, Gwendolen Road, Leicester LE5 4PW, UK; sudesna. chatterjee@uhl-tr.nhs.uk

Received 30 April 2015 Revised 10 August 2015 Accepted 12 September 2015

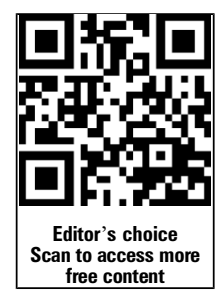

\section{ABSTRACT}

The last 90 years have seen considerable advances in the management of type 1 and type 2 diabetes. Prof MacLean of Guy's Hospital wrote in the Postgraduate Medical Journal in 1926 about the numerous challenges that faced patients and their healthcare professionals in delivering safe and effective diabetes care at that time. The discovery of insulin in 1922 heralded a new age in enabling longterm glycaemic control, which reduced morbidity and mortality. Thirty years later, the first oral agents for diabetes, the biguanides and sulfonylureas, appeared and freed type 2 patients from having to inject insulin following diagnosis. Improvements in insulin formulations over the decades, including rapid-acting and long-acting insulin analogues that more closely mimic physiological insulin secretion, have increased the flexibility and efficacy of type 1 diabetes management. The last two decades have seen major advances in technology, which has manifested in more accurate glucose monitoring systems and insulin delivery devices ('insulin pump'). Increased understanding of the pathophysiological deficits underlying type 2 diabetes has led to the development of targeted therapeutic approaches such as on the small intestine (glucagon-like peptide-1 receptor analogues and dipeptidyl-peptidase IV inhibitors) and kidneys (sodiumglucose cotransporter-2 inhibitors). A patient-centred approach delivered by a multidisciplinary team is now advocated. Glycaemic targets are set according to individual circumstances, taking into account factors such as weight, hypoglycaemia risk and patient preference. Stepwise treatment guidelines devised by international diabetes organisations standardise and rationalise management. Structured education programmes and psychological support are now well-established as essential for improving patient motivation and self-empowerment. Large multicentre randomised trials have confirmed the effectiveness of intensive glycaemic control on microvascular outcomes, but macrovascular outcomes and cardiovascular safety remain controversial with several glucose-lowering agents. Future directions in diabetes care include strategies such as the 'bionic pancreas', stem cell therapy and targeting the intestinal microbiome. All of these treatments are still being refined, and it may be several decades before they are clinically useful. Prevention and cure of diabetes is the Holy Grail but remain elusive due to lack of detailed understanding of the metabolic, genetic and immunological causes that underpin diabetes. Much progress has been made since the time of Prof MacLean 90 years ago, but there are still great strides to be taken before the life of the patient with diabetes improves even more significantly.

\section{INTRODUCTION}

In 1926, when Prof MacLean, Professor of Medicine at St. Thomas' Hospital, London, wrote his article on 'Some Observations on Diabetes and Insulin in General Practice' in the Postgraduate Medical Journal, ${ }^{1}$ the discovery of insulin was not yet 5 years old. Nevertheless, Prof MacLean was convinced that "insulin is by far the greatest boon that has ever been conferred on the suffering diabetic patient, for through its proper use he may, in almost every instance, regain a great measure of health and strength".

Ninety years on, the management of type 1 and type 2 diabetes focuses on improving glycaemic control by means of lifestyle modification and pharmacological therapy with the aim of reducing risk and progression of microvascular and macrovascular complications. Landmark studies such as the Diabetes Control and Complications Trial (DCCT) in type 1 diabetes and the United Kingdom Diabetes Prospective Study (UKPDS) in type 2 diabetes have shown that intensive glycaemic control improves patient outcomes especially for microvascular complications although the effect on macrovascular complications remains unresolved. ${ }^{2} 3$ Diabetes care is delivered holistically by a multidisciplinary team (MDT) in primary and secondary care with the emphasis on individual glycaemic targets according to patient circumstances such as hypoglycaemia risk, weight and comorbidities. Patients are actively encouraged to self-manage their condition and engage in the decision-making process with the support of this team. The use of technology has transformed the monitoring and delivery of treatment in diabetes and communication with healthcare professionals while new glucose-lowering therapies are used to target key pathophysiological defects in the development of diabetes.

Despite major advances in care, the prevention and cure of diabetes remain elusive. However, considerable research is being conducted in these areas and early results of trials indicate that it is unlikely to be another 90 years before prevention or cure will be realised for type 1 and type 2 diabetes. ${ }^{4} 5$ This review will discuss the current management of type 1 and type 2 diabetes, and also consider future directions in care, comparing the major changes since Prof MacLean's time 90 years ago and illustrating using his own words how our thoughts and understanding of this chronic condition have developed over the decades.

\section{LIFESTYLE MODIFICATION, STRUCTURED EDUCATION AND SELF-MANAGEMENT}

In 1926, Prof MacLean stated that "there are only two methods by which we can hope to do any good to the diabetic patient:-(a) by the use of suitable diet, and (b) by giving insulin. No drugs given 
by mouth have any influence whatever on the disease". It was recognised that overweight and obesity were contributory factors in the development of diabetes or 'hepatic glycosuria' and that in these cases "all that is required in many cases is to cut down the amount of food normally consumed; the carbohydrate of the diet must be more or less specially restricted, and the patient should live largely on protein and fat...these patients are usually too fat to begin with, and feel much better when their weight is considerably reduced".

The introduction of insulin following its discovery by Banting and Best in 1922 heralded a new age of diabetes management, which was no longer reliant on severely carbohydrate-restricted diets. ${ }^{6}$ While this still remains the case for the management of type 1 diabetes today, very low calorie diets are being used to manage type 2 diabetes and have even been shown to reverse the condition. ${ }^{7}$ Bariatric surgery such as Roux-en-Y gastric bypass or sleeve gastrectomy can also lead to improved glycaemic control through significant weight loss. ${ }^{8}$ Thirty years after the discovery of insulin, oral therapies such as sulfonylureas $(\mathrm{SU})^{9}$ and biguanides ${ }^{10}$ became available for the treatment of type 2 diabetes. Almost a century later, oral therapies are also being considered for type 1 diabetes in the form of sodiumglucose cotransporter-2 (SGLT-2) inhibitors ${ }^{11}$ and dipeptidylpeptidase IV (DPP-IV) inhibitors. ${ }^{12}$

Structured education programmes are considered essential to improve patient motivation, self-management skills and empowerment. The teaching of carbohydrate counting principles and insulin management skills in the Dose Adjustment for Normal Eating programme to patients with type 1 diabetes has been shown to improve quality of life and glycaemic control and is also cost-effective. ${ }^{13-15}$ Structured education on reduced calorie intake and increased physical activity for type 2 diabetes is provided through self-management and lay educator support in the Diabetes Education and Self-Management for Ongoing and Newly Diagnosed (DESMOND) programme, which demonstrated significant improvement in weight loss, smoking rates, depression levels and cardiovascular risk scores with nonsignificant improvements in physical activity, illness beliefs and glycaemic control. ${ }^{16}$ At 3-year follow-up following the 'one-off' intervention, there continued to be improvement in illness beliefs but no other sustained improvements in biomedical or lifestyle outcomes in DESMOND participants, emphasising the need for ongoing education and self-management support. ${ }^{17}$

\section{PHARMACOLOGICAL THERAPIES}

\section{Current management of type 2 diabetes}

The pharmacological management of type 2 diabetes is based on altering the effects of the 'ominous octet' that lead to hyperglycaemia. ${ }^{18}$ The eight pathophysiological mechanisms include reduced insulin secretion from pancreatic $\beta$ cells, increased glucagon secretion from pancreatic $\alpha$ cells, increased hepatic glucose production, neurotransmitter dysfunction and insulin resistance in the brain, increased lipolysis, increased renal glucose reabsorption, reduced incretin effect in the small intestine and reduced glucose uptake in peripheral tissues such as skeletal muscle, liver and adipose tissue. Currently available glucose-lowering therapies target one or more of these key components (figure 1).

\section{Oral therapies}

Metformin and SU have been available for the treatment of type 2 diabetes since the 1950s and remain first and secondline choices following diagnosis. Recent work has identified that metformin selectively inhibits the mitochondrial isoform of glycerophosphate dehydrogenase, reduces cytosolic dihydroxyacetone phosphate and raises cytosolic NADH-NAD ratio, all of which result in reduction in plasma glucose and lactate levels, reduced gluconeogenesis, hepatic glucose secretion and endogenous glucose production. ${ }^{19}$ There is also inhibition of food intake possibly by glucagon-like peptide-1 (GLP-1)-mediated effects. ${ }^{20}$ Metformin is effective at reducing HbA1c with no risk of hypoglycaemia while being weight neutral or even achieving weight loss. Apart from the rare side effect of lactic acidosis, seldom seen in clinical practice unless there is organ failure, metformin is relatively safe although up to $30 \%$ of patients experience troublesome gastrointestinal side effects. Metformin can be used with all other diabetes therapies including insulin and is also used regularly in the management of gestational diabetes and polycystic ovary syndrome. Metformin is associated with improved cardiovascular outcomes in patients with diabetes ${ }^{3}$ and may also reduce cancer risk. $^{21}$

Insulin sensitisers such as SU and meglitinides stimulate insulin secretion from the $\beta$ cells of the pancreas and are thus associated with hypoglycaemia and weight gain. They are effective at reducing HbA1c and rapidly lower glucose levels, which is useful in highly symptomatic patients following diagnosis. Older generation SU such as tolbutamide and glibenclamide have been superseded by new versions such as glimepiride, which are shorter-acting reducing risk of hypoglycaemia and more effective, although more expensive. It is not clear how SU affect the risk of cardiovascular complications, ${ }^{22}$ and $\beta$ cell exhaustion is often postulated to reduce long-term efficacy. In the A Diabetes Outcome Progressions Trial, glyburide demonstrated less durable control compared with metformin and rosiglitazone. ${ }^{23}$

In the last three decades, several new classes of diabetes oral therapies have been introduced. Thiazolidinediones (TZD, PPAR $\gamma$ agonists) have been available for around 20 years. Mechanisms of action include reduced free fatty acid accumulation, decrease in inflammatory cytokines, increase in adiponectin levels and preservation of $\beta$ cell structure and function, all leading to improvement in insulin resistance and $\beta$ cell failure. ${ }^{24}$ The first in class, troglitazone, was effective at improving glycaemic control and insulin resistance but was withdrawn from the market following several cases of liver failure. ${ }^{25}$ More recent controversies with these agents have been the association of rosiglitazone with increased cardiovascular morbidity and mortality $^{26}$ and pioglitazone with bladder cancer, ${ }^{27}$ although recent data have provided some reassurance. In carefully selected patients, pioglitazone can be useful for managing type 2 diabetes. ${ }^{24}$ The incretin therapies include the subcutaneously injectable GLP-1 receptor agonists, exenatide, liraglutide, lixisenatide, dulaglutide and albiglutide, and the oral DPP-IV inhibitors sitagliptin, saxagliptin, vildagliptin, linagliptin and alogliptin. GLP-1 receptor agonists activate GLP-1 receptors in the small intestine and DPP-IV inhibitors inactivate the enzyme DPP-IV, which normally breaks down GLP-1. These medications increase insulin secretion via $\beta$ cells as well as reduce glucagon secretion, hepatic glucose production and glucose uptake from the stomach and promote satiety. All these actions result in improved glycaemic control (HbA1c reduction up to 1.6\%) with minimal risk of hypoglycaemia and often significant weight loss (up to $8 \mathrm{~kg}$ ) with GLP-1 agonists and weight neutrality with DPP-IV inhibitors. ${ }^{28}$ GLP-1 agonists can be used in conjunction with insulin to optimise control, reduce its weight gain effects and lower daily insulin dose requirements. ${ }^{29}$ Currently in the UK, they are licensed by the National Institute for Health and Care Excellence (NICE) for use as triple therapy in type 2 patients with body 


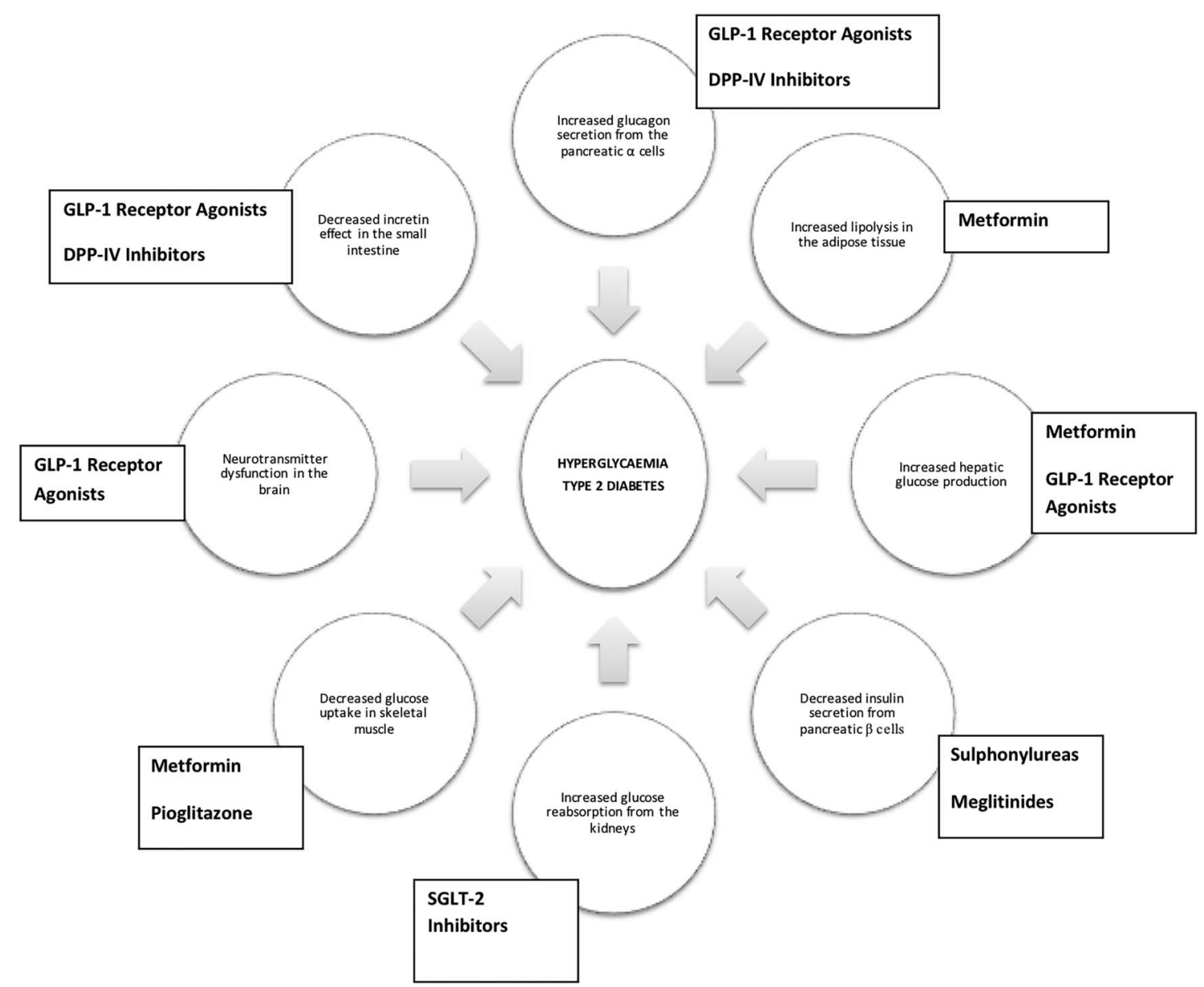

Figure 1 The ominous octet and the target sites for glucose-lowering therapies. DPP-IV, dipeptidyl-peptidase IV; GLP-1, glucagon-like peptide-1; SGLT-2, sodium-glucose cotransporter-2.

mass index $(\mathrm{BMI}) \geq 35 \mathrm{~kg} / \mathrm{m}^{2}$ or $\mathrm{BMI} \geq 30 \mathrm{~kg} / \mathrm{m}^{2}$ if comorbidities such as obstructive sleep apnoea or occupational issues precluding insulin are present. ${ }^{30}$ DPP-IV inhibitors can be used safely in worsening renal impairment, with some agents such as linagliptin, which is mainly excreted enterohepatically requiring no dose adjustment even in end-stage renal failure.

The newest agents licensed for type 2 diabetes are the SGLT-2 inhibitors. These agents inhibit SGLT-2 found on the proximal convoluted tubule of the nephron, which are responsible for reabsorption of $>90 \%$ of glucose from the urinary filtrate, resulting in increased urinary glucose excretion that leads to improved glycaemic control with no risk of hypoglycaemia and moderate amounts of weight loss. ${ }^{31}$ SGLT-2 inhibitors such as dapagliflozin, canagliflozin and empagliflozin can be used as second-line or third-line agents in the treatment of type 2 diabetes or in combination with insulin. ${ }^{32}$ Based on their mechanism of action, they could potentially be a useful treatment for type 1 diabetes as seen with empagliflozin in rodent models treated with streptozotocin. ${ }^{33}$

Several organisations including American Diabetes Association, European Association for the Study of Diabetes and NICE have produced algorithms providing guidance on the stepwise addition of glucose-lowering therapies based on HbA1c targets, efficacy, weight and hypoglycaemia risk and cost (figure 2). ${ }^{30} 3435$ Table 1 summarises the oral and injectable glucose-lowering therapies currently licensed in the UK. Polypharmacy, especially in older patients with other comorbidities, can be associated with diminishing concordance particularly when combined with blood pressure, lipid lowering and antiplatelet therapy, which form part of the routine management of diabetes. A recent analysis suggests that clinical benefit is gained by ensuring concordance in type 1 and type 2 diabetes despite the patient burden of polypharmacy. ${ }^{36}$

Insulin formulations and delivery in the management of type 1 and type 2 diabetes

Modern developments in insulin therapy have resulted in more physiological combinations of insulin allowing greater flexibility in regimen and tailored to the patient's needs. Long-acting insulins such as glargine and detemir and ultra-long-acting insulins such as degludec can be combined with rapid-acting insulins such as aspart and lispro to provide effective basal bolus therapy more closely reflecting physiological insulin secretion. Degludec, the most recently launched insulin on the market, has an ultralong duration of action and compared with other basal insulins such as glargine is associated with less pharmacodynamic variability and a more stable action profile, resulting in equivalent control and less frequent nocturnal hypoglycaemia. ${ }^{37}$ Hypoglycaemia and weight gain remain the two significant side effects of intensive insulin therapy. Severe hypoglycaemia has been linked with increased cardiovascular morbidity and mortality. ${ }^{38} 39$ Weight gain, in particular, can be a barrier to the use of insulin in type 2 diabetes and in the UKPDS patients gained $6 \mathrm{~kg}$ with insulin therapy compared with $1.7-2.6 \mathrm{~kg}$ with SU. ${ }^{40}$ 

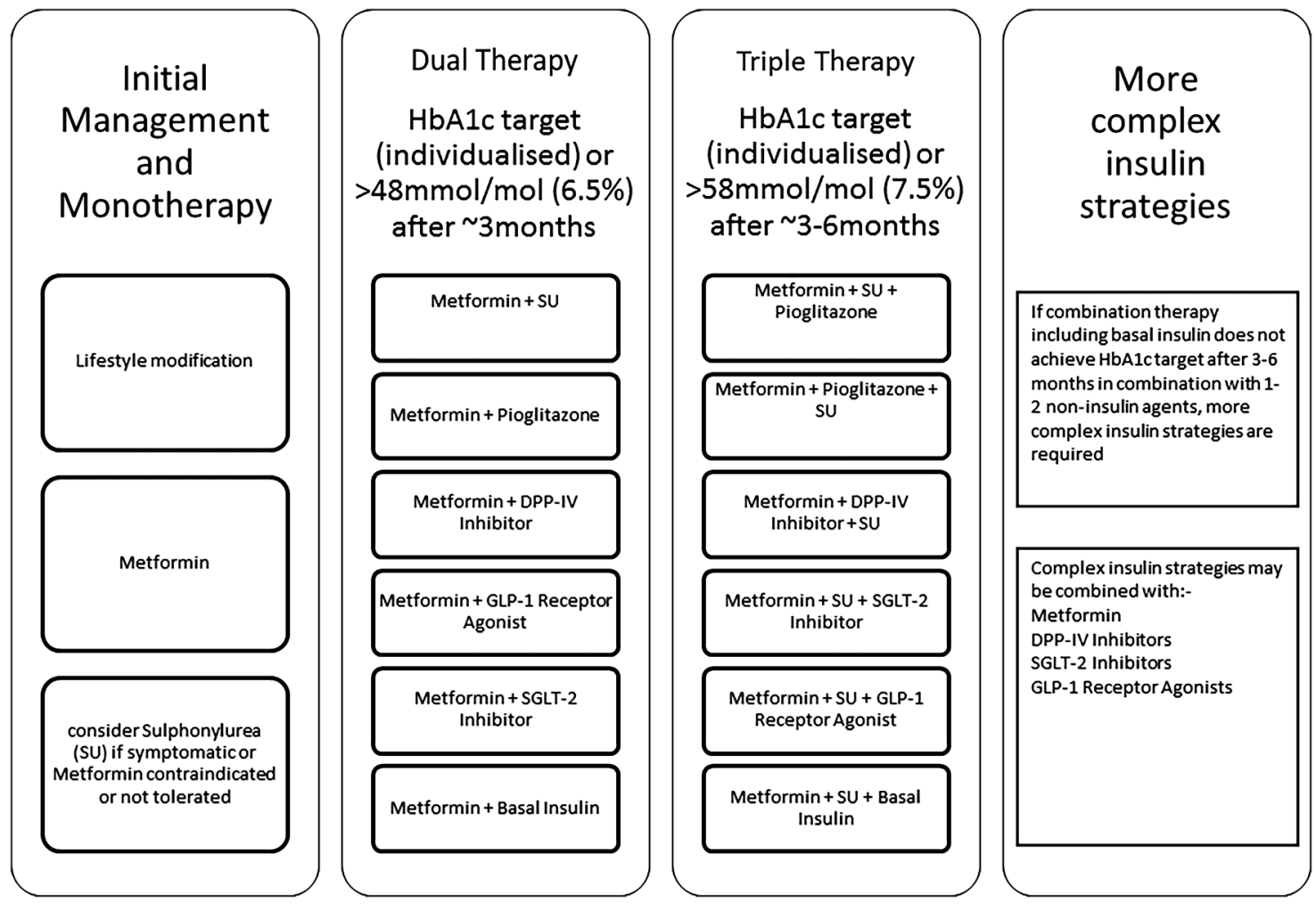

Figure 2 Antihyperglycaemic treatment of type 2 diabetes (based on the National Institute for Health and Care Excellence and the American Diabetes Association/European Association for the Study of Diabetes recommendation. DPP-IV, dipeptidyl-peptidase IV; GLP-1, glucagon-like peptide-1; SGLT-2, sodium-glucose cotransporter-2.

More recently, the combination of GLP-1 receptor agonists and insulin has been beneficial in managing the weight gain associated with insulin and the need for high doses in the presence of significant insulin resistance. ${ }^{29}$

Reluctance to commence insulin therapy was an issue in 1926 and remains present today due to factors such as fear of hypoglycaemia, weight gain and needle phobia in patients and clinical inertia on the part of healthcare professionals.

\begin{abstract}
"Frequently patients refuse insulin because they think that once they begin to have it insulin must be administered for the remainder of their lives. This is an entirely erroneous view, for there is nothing whatever in insulin treatment which necessitates its continuous use; indeed, it is frequently used for short periods in getting certain patients into the best possible condition for operation. It is quite true that in the majority of cases of severe diabetes insulin has to be continued for the rest of the patient's life, but this is only the case because of the disease being so severe that without insulin death would quickly ensue."
\end{abstract}

In 1926, the administration of insulin required the use of large glass syringes and needles. Insulin was impure and frequently resulted in infection and lipoatrophy at the injection site. Prior to the era of pre-mixed insulin, insulin analogues and pen devices, injections were painful, frequent and inconvenient. Lipoatrophy is very rare now, although lipohypertrophy due to failure to rotate injection sites is still a common cause of poor insulin absorption and suboptimal glycaemic control. Insulin remains the only realistic treatment option for type 1 diabetes, although now it may be administered either by multiple dose injection (MDI) or continuous subcutaneous insulin infusion (CSII)—the 'insulin pump'. Continuous glucose monitoring systems can improve the efficacy of $\mathrm{MDI}^{41}$ and reduce rate of severe hypoglycaemia with CSII. ${ }^{42}$ Attempts to manufacture oral insulin formulations that are not degraded in the stomach continue in the meantime. ${ }^{43}$ Inhaled insulin therapy is being relaunched following improved design of the delivery device in the last five years but concerns remain with regard to long-term efficacy and pulmonary safety. ${ }^{44}$

Interestingly, Prof MacLean's assertion that insulin does not need to be continued long term has some basis in modern times. In the relatively rare monogenic forms of diabetes known as maturity onset diabetes in the young (MODY) due in most cases to mutations in glucokinase or hepatic nuclear factor genes, patients may initially be misdiagnosed as type 1 or type 2 diabetes and commenced on insulin only to be later confirmed as having MODY and subsequently managed quite adequately on diet or, in some cases, SU therapy. ${ }^{45}$ Another form of diabetes that can be misdiagnosed as type 2 diabetes is latent autoimmune diabetes in adults, a slowly progressive autoimmune condition of late adult onset (usually $>35$ years), which is initially managed on oral therapy for at least six months after diagnosis but thereafter requires insulin treatment. Some studies have also shown that use of subcutaneous or intravenous insulin in the first few weeks following diagnosis of type 2 diabetes can ameliorate glucotoxicity and preserve $\beta$ cell function. ${ }^{46}$ Once glycaemic control is achieved with early insulin therapy, oral hypoglycaemic agents can be commenced. Concerns over increased hypoglycaemia risk, weight gain, unclear cancer risk and lack of trial data of positive cardiovascular outcomes support discontinuation of insulin therapy following early initiation and stabilisation of glucose levels. ${ }^{47}$ 
Table 1 Non-insulin glucose-lowering therapies currently licensed for type 2 diabetes management

\begin{tabular}{|c|c|c|c|c|c|c|}
\hline Therapy & Dose and frequency & Efficacy & Effect on weight & Adverse effects & Safety & Cost \\
\hline \multicolumn{7}{|l|}{ Oral administration } \\
\hline \multicolumn{7}{|l|}{ Biguanides } \\
\hline Metformin & $0.5-2.5 \mathrm{~g}$ daily & \multirow[t]{2}{*}{$\mathrm{HbA} 1 \mathrm{c} \downarrow \sim 1 \%$} & \multirow[t]{2}{*}{ Weight neutral or weight loss } & \multirow[t]{2}{*}{ Nausea, vomiting, bloating, diarrhoea, flatulence } & Not safe in moderate/severe renal impairment & \multirow[t]{2}{*}{ Low } \\
\hline Glucophage SR & $0.5-2.0 \mathrm{~g}$ daily & & & & $\begin{array}{l}\text { Risk of lactic acidosis (rare) } \\
\text { Vitamin B12 deficiency }\end{array}$ & \\
\hline \multicolumn{7}{|l|}{ Sulfonylureas, eg, } \\
\hline Gliclazide & 40-160 mg daily & \multirow[t]{2}{*}{$\mathrm{HbA} 1 \mathrm{c} \downarrow \sim 1 \%$} & \multirow[t]{2}{*}{ Weight gain } & \multirow[t]{2}{*}{ Hypoglycaemia, weight gain } & \multirow[t]{2}{*}{ ? Long-term cardiovascular effects } & \multirow[t]{2}{*}{ Low } \\
\hline Glimepiride & 1-6 mg daily & & & & & \\
\hline \multicolumn{7}{|l|}{ TZDs } \\
\hline Pioglitazone & 15-45 mg daily & $\mathrm{HbA} 1 \mathrm{c} \downarrow \sim 1 \%$ & Weight gain & Weight gain, peripheral oedema & Heart failure, bone fractures, ? Bladder cancer & Low \\
\hline \multicolumn{7}{|l|}{ Meglitinides } \\
\hline Repaglinide & $0.5-16 \mathrm{mg}$ daily & $\mathrm{HbA} 1 \mathrm{c} \downarrow 0.5-0.8 \%$ & Weight gain & Hypoglycaemia, weight gain & ? Long-term cardiovascular effects & High \\
\hline \multicolumn{7}{|l|}{ DPP-IV inhibitors } \\
\hline Sitagliptin & 25-100 mg daily & \multirow[t]{5}{*}{$\mathrm{HbA} 1 \mathrm{c} \downarrow 0.8-1 \%$} & \multirow[t]{5}{*}{ Weight neutral } & \multirow{5}{*}{$\begin{array}{l}\text { Nasopharyngitis, upper respiratory tract infections, } \\
\text { headache (all very rare) }\end{array}$} & \multirow{5}{*}{$\begin{array}{l}\text { Can be used in moderate renal impairment } \\
\text { ? Long-term cardiovascular effects } \\
\text { ? Heart failure }\end{array}$} & \multirow[t]{5}{*}{ High } \\
\hline Linagliptin & $5 \mathrm{mg}$ daily & & & & & \\
\hline Saxagliptin & $2.5-5 \mathrm{mg}$ daily & & & & & \\
\hline Vildagliptin & 50-100 mg daily & & & & & \\
\hline Alogliptin & $6.25-25 \mathrm{mg}$ daily & & & & & \\
\hline \multicolumn{7}{|l|}{ SGLT-2 inhibitors } \\
\hline Dapagliflozin & 5-10 mg daily & HbA1c & \multirow[t]{3}{*}{ Weight loss } & \multirow{3}{*}{$\begin{array}{l}\text { Urinary frequency, urinary tract and mycotic genital } \\
\text { infections, volume depletion }\end{array}$} & \multirow{3}{*}{$\begin{array}{l}\text { Not effective with renal impairment } \\
\text { ? Long-term cardiovascular effects }\end{array}$} & \multirow[t]{3}{*}{ High } \\
\hline Canagliflozin & $100-300 \mathrm{mg}$ daily & $\downarrow \sim 1 \%$ & & & & \\
\hline Empagliflozin & $10-25 \mathrm{mg}$ daily & & & & & \\
\hline \multicolumn{7}{|c|}{ Subcutaneous injection } \\
\hline \multicolumn{7}{|c|}{ GLP-1 receptor agonists } \\
\hline Exenatide & 5-10 $\mu$ g daily & \multirow[t]{6}{*}{$\mathrm{HbA} 1 \mathrm{c} \downarrow \sim 1-1.5 \%$} & \multirow[t]{6}{*}{ Weight loss } & \multirow[t]{6}{*}{ Nausea, vomiting } & \multirow{6}{*}{$\begin{array}{l}\text { Use with caution in moderate and avoid with } \\
\text { severe renal impairment } \\
\text { Acute pancreatitis, C-cell hyperplasia/medullary } \\
\text { thyroid tumours in animals }\end{array}$} & Very high \\
\hline Exenatide LA & $2 \mathrm{mg}$ weekly & & & & & \\
\hline Liraglutide & $0.6-1.8 \mathrm{mg}$ daily & & & & & \\
\hline Lixisenatide & $10-20 \mu \mathrm{g}$ daily & & & & & \\
\hline Albiglutide & $30 \mathrm{mg}$ weekly & & & & & \\
\hline Dulaglutide & $0.75-1.5 \mathrm{mg}$ weekly & & & & & \\
\hline
\end{tabular}




\section{DIABETES MONITORING}

\section{Current management}

Monitoring the efficacy of diabetes control has improved with the introduction of better techniques for identifying elevated urinary and plasma glucose and ketone levels. Prof MacLean wrote that "when diet is tried in a true diabetic case the method adopted is to starve the patient until the urine is free from sugar, and then to give gradually increasing amounts of food until a diet is obtained which contains the necessary amount of nourishment for the patient without producing glycosuria or ketosis".

Urinary glucose monitoring is now only used infrequently as a method for indicating good control and has been superseded by plasma glucose monitoring especially when patients are on insulin or glucose-lowering treatments that can cause hypoglycaemia. However, urinary glucose monitoring is not appropriate in patients on SGLT-2 inhibitors as glycosuria is the mechanism of action. Capillary glucose meters use increasingly sophisticated technology to increase patient safety and overall user experience, for example, by enabling graphs to be downloaded on a computer, connecting to mobile phone apps and helping to adjust insulin doses according to carbohydrate portions. While continuous glucose monitoring cannot be provided to most patients due to cost and complexity, self-monitoring of plasma glucose remains a patient-friendly, cheap and portable method, and a recent study confirmed that reasonable accuracy can be obtained in clinical practice. ${ }^{48}$ Plasma ketone meters can help increase safety by indicating if an unwell patient with type 1 diabetes is developing ketoacidosis and requires hospital admission. The very recent introduction of flash glucose monitoring devices (Abbott Freestyle Libre), which do not require any calibration with daily capillary glucose testing, may transform ease of monitoring in patients for whom frequent finger prick tests are necessary although they are not yet available via the National Health Service.

Since the 1970s, glycosylated haemoglobin (HbA1c), which is based on the glycosylation of the terminal A1c portion of the haemoglobin molecule over the 120-day lifespan of the red blood cell, has been used to monitor the effectiveness of diabetes management. More recently, HbA1c measurements have been standardised internationally with the units changing from percentage to $\mathrm{mmol} / \mathrm{mol}^{49} \mathrm{HbA} 1 \mathrm{c}$ is now internationally accepted as a reliable test for diabetes diagnosis and screening.

\section{DIABETES INPATIENT CARE}

Diabetes is a disease in which the body is more or less incapable of using food; consequently, there results an accumulation of various waste products in the body which ultimately, in the absence of suitable treatment, give rise to the toxic condition known as diabetic coma.

Prof MacLean was concerned about the risks of untreated diabetes leading to coma that occur with either diabetic ketoacidosis (DKA) mainly in type 1 diabetes or hyperglycaemic hyperosmotic syndrome (HHS) in type 2 diabetes. These medical emergencies are associated with considerable morbidity and mortality, around 1\% for DKA and up to 20\% with HHS due to greater patient age and significant comorbidities. ${ }^{50}$ Considerable advances in intensive care therapy units have improved the risks associated with these emergencies, but patient and healthcare professional education is still required to reduce the risk of hospital admissions by reiterating the 'sick day rules' and ensuring timely assessment and treatment of precipitating factors such as infection. While the aim of diabetes management is to keep the patient out of hospital as much as possible, national inpatient guidelines and protocols have been developed to ensure that standards are maintained and length of stay is as short as possible. ${ }^{51}$ While not being the main cause for admission in the majority of cases, more than one in six hospital beds were filled by a patient with diabetes according to a UK national audit in 2014. ${ }^{52}$ Increased hyperglycaemia on admission is associated with longer length of stay, 28-day mortality and readmission. ${ }^{53}$ Iatrogenic errors due to delays in timing and administration of insulin and oral hypoglycaemic agents in diabetes inpatient care are a significant cause of morbidity and mortality. $^{54}$

The MDT approach is a cornerstone in the current management of diabetes both in hospital and in the community. The patient is likely to be in contact with numerous healthcare professionals during the course of their life including the consultant diabetologist, diabetes specialist nurse, dietitian, general practitioner, practice nurse, podiatrist, psychologist and many other specialties including ophthalmology, vascular surgery, cardiology, stroke and renal services. Holistic management with MDT support and engaging patients and their families in discussion regarding treatment is now considered the optimal strategy for diabetes care. ${ }^{55}$

\section{COMPLICATIONS}

Hepatic glycosuria is extremely uncommon in the young, but is very common in the aged and middle aged. It may give rise to certain symptoms such as neuritis, pruritus, retinitis, trophic disturbances, and general weakness of the muscles, but is never associated with the wasting and acidosis which accompanies true diabetes.

When Prof MacLean wrote his review, most patients with type 1 diabetes died early on in the disease due to lack of insulin, and he therefore assumed that the chronic macrovascular complications of cardiovascular, cerebrovascular and peripheral vascular disease and microvascular complications of retinopathy, nephropathy and neuropathy, only afflicted those with type 2 diabetes. Nearly a century later, these complications remain a significant cause of morbidity and mortality in both types of diabetes, especially if glycaemic control and associated conditions such as hypertension and hyperlipidaemia and lifestyle factors such as smoking and obesity are not adequately managed. Complications are often detected at diagnosis in patients with type 2 diabetes as it can remain undiagnosed for up to 12 years before presentation. In type 1 diabetes, complications usually develop $10-15$ years following diagnosis. The annual review is an important way of monitoring for complications and ensuring timely referral to appropriate specialist services.

\section{Cardiovascular disease}

Patients with diabetes have a higher risk of cardiovascular mortality compared with the general population. ${ }^{56}$

The management of cardiovascular risk factors is paramount to good diabetes outcomes. Patients should be encouraged to stop smoking, consume a low-fat low-sugar diet, increase physical activity, reduce alcohol consumption and achieve normal body weight in order to minimise the risk of cardiovascular events. Often, patients are managed with multiple agents including antihypertensive medications (three or more different classes can be necessary), lipid-lowering agents such as statins and antiplatelet agents such as aspirin.

Improved cardiovascular outcomes are achieved by intensive management in type 1 diabetes as indicated by Epidemiology of 
Diabetes Intervention and Complications (EDIC), a 9-year follow-up of the DCCT cohort. ${ }^{2}$

Interestingly, this has not been demonstrated as conclusively in type 2 diabetes with studies such as UKPDS, ${ }^{40}$ Action in Diabetes and Vascular disease: PreterAx and Diamicron-MR Controlled Evaluation (ADVANCE), ${ }^{57}$ Action to Control Cardiovascular Risk in Diabetes (ACCORD) ${ }^{58}$ and Veterans Affairs and Diabetes Trial. ${ }^{59}$

A legacy effect of previous intensive glucose and blood pressure control leading to improvement in cardiovascular outcomes was demonstrated by both DCCT-EDIC and UKPDS. ${ }^{3}$

The increased thrombotic tendency associated with diabetes indicates that antiplatelet therapy would be beneficial. While the use of aspirin for secondary prevention in diabetes is established by large trials, ${ }^{60}$ the evidence for primary prevention is less well substantiated in two trials showing no significant benefit. ${ }^{61} 62$

The results of large-scale multicentre randomised controlled trials such as Aspirin and simvastatin Combination for Cardiovascular Events Prevention Trial in Diabetes ${ }^{63}$ are awaited to confirm the efficacy of aspirin in primary prevention.

\section{Microvascular complications}

Diabetes remains the most common cause of blindness in the working age group of the Western world. The establishment of national retinal screening programmes in the UK has improved the detection and early referral to ophthalmology services of patients with diabetic retinopathy and maculopathy. Panretinal photocoagulation and newer therapies such as injectable inhibitors of vascular endothelial growth factor can prevent worsening of proliferative retinopathy and onset of visual impairment. ${ }^{64}$

Patients with diabetic foot ulcers due to peripheral neuropathy and/or vascular disease are at risk of gangrene and amputation. Multidisciplinary foot clinics involving diabetologists, diabetes specialist nurses, podiatrists, vascular surgeons and microbiologists can ensure that acute ulcers are managed using established guidelines to effectively reduce the risk of eventual amputation and significant deterioration in quality of life for patients. $^{65} 66$

End-stage renal disease leading to dialysis and/or renal transplantation is most commonly due to diabetes in the Western world. Screening for early signs of renal disease by measuring renal function and urinary albumin-creatinine ratio (ACR) annually ensures that management can be optimised and drugs such as ACE inhibitors that normalise ACR and/or reduce the progression of chronic kidney disease can be introduced in a timely fashion. ${ }^{67}$

\section{FUTURE DIRECTIONS OF CARE}

This glycosuria is usually not serious, and may go on for 20 years or more without causing any bad effects, while true diabetes, unless treated by insulin, usually proves fatal in from four to five years.

Prof MacLean's prognosis remains true to this day in that insulin remains the only treatment option for type 1 diabetes and the eventual therapy for type 2 diabetes. However, the Holy Grail in diabetes research is prevention and cure of this insidious disease that can only be achieved by preserving or increasing $\beta$ cell function and mass using strategies such as immunomodulation, immunoisolation and pharmacological therapies. ${ }^{4}$ Prevention of type 1 diabetes remains elusive due to a lack of understanding of the underlying metabolic, genetic and immunological causes for its development. ${ }^{4}$ Prevention of type 2 diabetes by optimising lifestyle modification or using metformin in pre-diabetes has been adequately demonstrated by clinical trials such as the Diabetes Prevention Program but is difficult to translate into real-world clinical practice. ${ }^{68}$

There has been some interesting work in immunomodulation using antigen-specific and non-antigen-specific agents. For example, glutamate decarboxylase 65 has been identified as an antigen-specific immune agent that can reverse $\beta$ cell destruction in mice, ${ }^{69}$ although this has not been replicated yet in human models. $^{70}$ In the future, stem cell therapy may prove to be a way of curing diabetes. Autologous non-myeloablative haematopoietic stem cell transplantation preceded by high-dose cyclophosphamide has been shown to increase C-peptide levels and insulin independence in 93\% of newly diagnosed type 1 diabetes patients, although the mechanism of action remains unclear. $^{71}$

There has been much pioneering work on whole pancreas and islet cell transplantation, which offers a real hope of cure. Transplantation is currently restricted to those with disabling hypoglycaemia or highly erratic glycaemic control and is limited by scarcity of donor tissue and specialist transplant centres as well as problems with transplant rejection and side effects of immunosuppressive drugs. ${ }^{72}$ Between 2007 and 2010, it was reported by the Collaborative Islet Transplant Registry that 44\% of islet cell recipients were insulin independent at 3 years, almost double that a decade earlier. ${ }^{73}$ This improvement has been achieved by standardised management through the Edmonton protocol, better immunosuppression strategies and improved islet engraftment. ${ }^{72}$

Meanwhile, technological advances have resulted in a mechanical implantable pancreas, which does not require any input from the patient with regard to insulin administration or glucose monitoring. For example, an artificial bihormonal pancreas, delivering both insulin and glucagon, has been compared with standard insulin pump therapy and has been shown to be clinically beneficial in type 1 diabetes. ${ }^{74}$ With this 'bionic' pancreas, the device automatically senses glucose levels and sends these data to the insulin delivery system to enable the accurate administration of an algorithm-derived dosage of insulin. Participants were able to achieve better glycaemic control without hypoglycaemia with this device over 5 days compared with pump therapy. ${ }^{74}$ As the technology is still relatively underdeveloped, it is likely to take several more years, if not decades, before this device is routinely available in clinical practice. The intestinal microbiome is a focus of considerable therapeutic interest in the management of obesity and type 2 diabetes. ${ }^{75}$ Changes have been observed in the microbiota composition of obese subjects, which may respond to interventions such as faecal transplantations. As obesity is one of the major risk factors for type 2 diabetes, such manipulations may be a future pathway for prevention.

\section{CONCLUSION}

Ninety years ago, at the dawn of insulin discovery, Prof MacLean clearly highlighted in his Postgraduate Medical Journal article the considerable challenges faced by patients diagnosed then with diabetes and outlined his strategies for optimising care. Many decades later in the early 21st century, the focus of modern diabetes management is to provide holistic and individualised patient care based on structured education, selfmanagement and safe and effective glucose-lowering therapies while modifying cardiovascular risk factors, especially as cardiovascular disease remains the commonest cause of mortality for patients with diabetes. As our understanding grows of the 
underlying pathophysiological mechanisms for hyperglycaemia, more targeted treatments and procedures continue to be successfully developed. As a consequence, we can hope that, in the next 90 years, there will be more effective management of the patient with diabetes, with strategies for prevention and ultimately cure of diabetes on the horizon.

\section{Main messages}

- Type 1 and type 2 diabetes are managed holistically by a combination of lifestyle modifications and glucose-lowering therapies.

- Structured education is now a well-established and essential component of type 1 and type 2 diabetes management.

- New classes of glucose-lowering therapies need to be combined with long-standing pre-existing therapies and individualised to the patient with regard to efficacy, hypoglycaemia risk, weight, adverse effects and cost.

- Technological advances in the late 20th and early 21st centuries have enabled better monitoring of glucose levels and alternative administration of insulin (the 'insulin pump').

\section{Current research questions}

- Can we restore $\beta$ cell function and mass to patients with diabetes and thus prevent its progression?

- What are the long-term cardiovascular benefits of currently available glucose-lowering therapies?

- Will the 'bionic pancreas' find a place in clinical diabetes management?

- What role will the intestinal microbiome play in the future management of diabetes and obesity?

- Can we find a cure for diabetes?

\section{Key references}

- Nathan DM, Cleary PA, Backlund JY, et al. Intensive diabetes treatment and cardiovascular disease in patients with type 1 diabetes. N Engl J Med 2005;353:2643-53.

- Holman RR, Paul SK, Bethel MA, et al. 10-year follow-up of intensive glucose control in type 2 diabetes. $N$ Engl J Med 2008;359:1577-1589.

- Defronzo RA. Banting lecture from the triumvirate to the ominous octet: a new paradigm for the treatment of type 2 diabetes mellitus. Diabetes 2009;58:773-95.

- Inzucchi SE, Bergenstal RM, Buse JB, et al. Management of hyperglycemia in type 2 diabetes, 2015: a patient-centered approach: update to a position statement of the American Diabetes Association and the European Association for the Study of Diabetes. Diabetes Care 2015;38:140-9.

- Bruni A, Gala-Lopez B, Pepper AR, et al. Islet cell transplantation for the treatment of type 1 diabetes: recent advances and future challenges. Diabetes Metab Syndr Obes 2014;7:211-23.

\section{Self-assessment questions}

1. Which of the following mechanisms are involved in the development of hyperglycaemia and type 2 diabetes as part of the ominous octet?

A. Reduced insulin secretion from pancreatic $\beta$ cells

B. Increased glucagon secretion from pancreatic $\alpha$ cells

C. Decreased hepatic glucose production

D. Brain neurotransmitter dysfunction

E. Decreased renal glucose reabsorption

2. Which of the following glucose-lowering drugs are currently licensed for treatment of type 2 diabetes in the UK?
A. Exenatide
B. Troglitazone
C. Metformin
D. Dapagliflozin
E. Glibenclamide

3. Which of the following are common side effects of current insulin therapy?
A. Hypoglycaemia
B. Lipoatrophy
C. Weight loss
D. Lipohypertrophy
E. Nausea and vomiting

4. Which of the following are considered to be landmark studies in patients with type 2 diabetes?

A. United Kingdom Prospective Diabetes Study (UKPDS)

B. Diabetes Control and Complications Trial (DCCT)

C. Action in Diabetes and Vascular Disease: PreterAx and Diamicron-MR Controlled Evaluation (ADVANCE)

D. Action to Control Cardiovascular Risk in Diabetes (ACCORD)

E. Diabetes Prevention Program (DPP)

5. Which of the following are areas of current diabetes research?
A. Autologous non-myeloablative haematopoietic stem cell transplantation preceded by high-dose cyclophosphamide
B. Artificial bihormonal pancreas - the 'bionic pancreas'
C. Transplantation of pancreatic $\alpha$ cells
D. Intestinal microbiome
E. Immunomodulation using antigen-specific and non- antigen-specific agents

Twitter Follow Sudesna Chatterjee at @DesChatterjee and Melanie J Davies at @profmjdavies

Contributors SC wrote the manuscript and MJD reviewed and advised on each draft.

Funding The authors acknowledge support from the National Institute for Health Research Collaboration for Leadership in Applied Health Research and Care-East Midlands (NIHR CLAHRC - EM), the Leicester Clinical Trials Unit, and the NIHR Leicester-Loughborough Diet, Lifestyle and Physical Activity Biomedical Research Unit, which is a partnership between the University Hospitals of Leicester NHS Trust, Loughborough University and the University of Leicester.

Disclaimer The views expressed are those of the authors and not necessarily those of the NHS, the NIHR or the Department of Health.

Competing interests None declared.

Provenance and peer review Commissioned; externally peer reviewed.

\section{REFERENCES}

1 Maclean $\mathrm{H}$. Some observations on diabetes and insulin in general practice. Postgrad Med J 1926;1:73-7. 
2 Nathan DM, Cleary PA, Backlund JY, et al. Intensive diabetes treatment and cardiovascular disease in patients with type 1 diabetes. $N$ Engl J Med 2005;353:2643-53.

3 Holman RR, Paul SK, Bethel MA, et al. 10-year follow-up of intensive glucose control in type 2 diabetes. N Engl J Med 2008;359:1577-89.

4 Skyler JS, Ricordi C. Stopping type 1 diabetes: attempts to prevent or cure type 1 diabetes in man. Diabetes 2011;60:1-8.

5 Bernal-Mizrachi E, Kulkarni RN, Scott DK, et al. Human $\beta$-cell proliferation and intracellular signaling part 2: still driving in the dark without a road map. Diabetes 2014;63:819-31.

6 Banting FG, Best $\mathrm{CH}$, Collip JB, et al. Pancreatic extracts in the treatment of diabetes mellitus. Can Med Assoc J 1922;12:141-6.

7 Dhindsa P, Scott AR, Donnelly R. Metabolic and cardiovascular effects of very-low-calorie diet therapy in obese patients with type 2 diabetes in secondary failure: outcomes after 1 year. Diabet Med 2003;20:319-24.

8 Schauer PR, Bhatt DL, Kashyap SR. Bariatric surgery versus intensive medical therapy for diabetes. N Engl J Med 2014;371:682.

9 Butterfield WJ, Camp JL, Hardwick C, et al. Clinical studies on the hypoglycaemic action of the sulphonylureas. Lancet 1957;269:753-6.

10 Krall LP, White P, Bradley RF. Clinical use of the biguanides and their role in stabilizing juvenile-type diabetes. Diabetes 1958;7:468-77.

11 Lamos EM, Younk LM, Davis SN. Empagliflozin, a sodium glucose co-transporter 2 inhibitor, in the treatment of type 1 diabetes. Expert Opin Investig Drugs 2014;23:875-82.

12 Miyagawa J, Miuchi M, Namba M. Incretin-based therapy in patients with type 1 diabetes mellitus. Nihon Rinsho 2011;69:923-9.

13 DAFNE Study Group. Training in flexible, intensive insulin management to enable dietary freedom in people with type 1 diabetes: dose adjustment for normal eating (DAFNE) randomised controlled trial. BMJ 2002;325:746.

14 Cooke D, Bond R, Lawton J, et al. Structured type 1 diabetes education delivered within routine care: impact on glycemic control and diabetes-specific quality of life. Diabetes Care 2013:36:270-2.

15 Kruger J, Brennan A, Thokala P, et al. The cost-effectiveness of the dose adjustment for normal eating (DAFNE) structured education programme: An update using the sheffield type 1 diabetes policy model. Diabet Med 2013;30:1236-44.

16 Davies MJ, Heller S, Skinner TC, et al. Effectiveness of the diabetes education and self management for ongoing and newly diagnosed (DESMOND) programme for people with newly diagnosed type 2 diabetes: cluster randomised controlled trial. BMJ 2008;336:491-5.

17 Khunti K, Gray LJ, Skinner T, et al. Effectiveness of a diabetes education and self management programme (DESMOND) for people with newly diagnosed type 2 diabetes mellitus: three year follow-up of a cluster randomised controlled trial in primary care. BMJ 2012;344:e2333.

18 Defronzo RA. Banting lecture. from the triumvirate to the ominous octet: a new paradigm for the treatment of type 2 diabetes mellitus. Diabetes 2009;58:773-95.

19 Madiraju AK, Erion DM, Rahimi Y, et al. Metformin suppresses gluconeogenesis by inhibiting mitochondrial glycerophosphate dehydrogenase. Nature 2014;510:542-6.

20 Mannucci $E$, Tesi $F$, Bardini $G$, et al. Effects of metformin on glucagon-like peptide-1 levels in obese patients with and without type 2 diabetes. Diabetes Nutr Metab 2004;17:336-42.

21 Soranna D, Scotti L, Zambon A, et al. Cancer risk associated with use of metformin and sulfonylurea in type 2 diabetes: a meta-analysis. Oncologist 2012;17:813-22.

22 Johnson JA. The safety of sulfonylurea therapy in type 2 diabetes: have we reached the practical limits of our evidence base? Diabetologia 2015;58:1-3.

23 Kahn SE, Lachin JM, Zinman B, et al. Effects of rosiglitazone, glyburide, and metformin on $\beta$-cell function and insulin sensitivity in ADOPT. Diabetes 2011;60:1552-60.

24 Consoli $A$, Formoso $G$. Do thiazolidinediones still have a role in treatment of type 2 diabetes mellitus? Diabetes Obes Metab 2013;15:967-77.

25 Kohlroser J, Mathai J, Reichheld J, et al. Hepatotoxicity due to troglitazone: report of two cases and review of adverse events reported to the united states food and drug administration. Am J Gastroenterol 2000;95:272-6.

26 Nissen SE, Wolski K. Effect of rosiglitazone on the risk of myocardial infarction and death from cardiovascular causes. N Engl J Med 2007:356:2457-71.

27 Kermode-Scott B. Meta-analysis confirms raised risk of bladder cancer from pioglitazone. BMJ 2012;345:e4541.

28 Deacon CF, Mannucci E, Ahrén B. Glycaemic efficacy of glucagon-like peptide-1 receptor agonists and dipeptidyl peptidase- 4 inhibitors as add-on therapy to metformin in subjects with type 2 diabetes-a review and meta analysis. Diabetes Obes Metab 2012;14:762-7

29 Buse JB, Bergenstal RM, Glass LC, et al. Use of twice-daily exenatide in basal insulin-treated patients with type 2 diabetes: a randomized, controlled trial. Ann Intern Med 2011;154:103-12.

30 NICE. Type 2 diabetes: the management of type 2 diabetes. 2009:CG87.

31 Tahrani AA, Barnett AH, Bailey CJ. SGLT inhibitors in management of diabetes. Lancet Diabetes Endocrinol 2013;1:140-51.

32 Vasilakou D, Karagiannis T, Athanasiadou E, et al. Sodium-glucose cotransporter 2 inhibitors for type 2 diabetes: a systematic review and meta-analysis. Ann Intern Med 2013;159:262-74.
33 Luippold G, Klein T, Mark M, et al. Empagliflozin, a novel potent and selective SGLT-2 inhibitor, improves glycaemic control alone and in combination with insulin in streptozotocin-induced diabetic rats, a model of type 1 diabetes mellitus. Diabetes Obes Metab 2012;14:601-7.

34 Inzucchi SE, Bergenstal RM, Buse JB, et al. Management of hyperglycaemia in type 2 diabetes: a patient-centered approach. Position statement of the American Diabetes Association (ADA) and the European Association for the Study of Diabetes (EASD). Diabetologia 2012;55:1577-96.

35 Inzucchi SE, Bergenstal RM, Buse JB, et al. Management of hyperglycemia in type 2 diabetes: a patient-centered approach: position statement of the american diabetes association (ADA) and the European Association for the Study of Diabetes (EASD). Diabetes Care 2012:35:1364-79.

36 Bauer S, Nauck MA. Polypharmacy in people with type 1 and type 2 diabetes is justified by current guidelines-a comprehensive assessment of drug prescriptions in patients needing inpatient treatment for diabetes-associated problems. Diabet Med 2014;31:1078-85.

37 Vora J, Christensen T, Rana A, et al. Insulin degludec versus insulin glargine in type 1 and type 2 diabetes mellitus: a meta-analysis of endpoints in phase 3 a trials. Diabetes Ther 2014;5:435-46.

38 Zoungas S, Patel A, Chalmers J, et al. Severe hypoglycemia and risks of vascular events and death. N Engl J Med 2010;363:1410-18.

39 Johnston SS, Conner C, Aagren $\mathrm{M}$, et al. Evidence linking hypoglycemic events to an increased risk of acute cardiovascular events in patients with type 2 diabetes. Diabetes Care 2011:34:1164-70.

40 [No authors listed]. Intensive blood-glucose control with sulphonylureas or insulin compared with conventional treatment and risk of complications in patients with type 2 diabetes (UKPDS 33). UK prospective diabetes study (UKPDS) group. Lancet 1998:352:837-53.

41 Tumminia A, Crimi S, Sciacca L, et al. Efficacy of real-time continuous glucose monitoring on glycaemic control and glucose variability in type 1 diabetic patients treated with either insulin pumps or multiple insulin injection therapy: a randomised controlled cross-over trial. Diabetes Metab Res Rev 2015:31:61-8.

42 Ly TT, Nicholas JA, Retterath A, et al. Effect of sensor-augmented insulin pump therapy and automated insulin suspension vs standard insulin pump therapy on hypoglycemia in patients with type 1 diabetes: a randomized clinical trial. JAMA 2013;310:1240-7.

43 Li P, Tan A, Prestidge CA, et al. Self-nanoemulsifying drug delivery systems for oral insulin delivery: in vitro and in vivo evaluations of enteric coating and drug loading. Int J Pharm 2014:477:390-8.

44 Rashid J, Absar S, Nahar K, et al. Newer devices and improved formulations of inhaled insulin. Expert Opin Drug Deliv 2015;12:917-28.

45 Thanabalasingham G, Pal A, Selwood MP, et al. Systematic assessment of etiology in adults with a clinical diagnosis of young-onset type 2 diabetes is a successful strategy for identifying maturity-onset diabetes of the young. Diabetes Care 2012;35:1206-12.

46 Weng J, Li Y, Xu W, et al. Effect of intensive insulin therapy on beta-cell function and glycaemic control in patients with newly diagnosed type 2 diabetes: A multicentre randomised parallel-group trial. Lancet 2008;371:1753-60.

47 Lebovitz HE. Insulin: potential negative consequences of early routine use in patients with type 2 diabetes. Diabetes Care 2011;34(Suppl 2):S225-30.

48 Gioe 0, Chalew SA. How well do self-monitored capillary glucose measurements predict the mean blood glucose from 24-hour continuous monitoring in endocrine practice? Endocr Pract 2014;20:650-6.

49 Braga F, Panteghini M. Standardization and analytical goals for glycated hemoglobin measurement. Clin Chem Lab Med 2013;51:1719-26.

50 Pasquel FJ, Umpierrez GE. Hyperosmolar hyperglycemic state: a historic review of the clinical presentation, diagnosis, and treatment. Diabetes Care 2014;37:3124-31.

51 Draznin B, Gilden J, Golden SH, et al. Pathways to quality inpatient management of hyperglycemia and diabetes: a call to action. Diabetes Care 2013:36:1807-14.

52 Health and Social Care Information Centre (HSCIC). Diabetes patients develop preventable complications in hospital and access to specialist staff is inadequate. http://www.hscic.gov.uk/article/4806/Diabetes-patients-develop-preventablecomplications-in-hospital-and-access-to-specialist-staff-is-inadequate. Updated 2014

53 Evans NR, Dhatariya KK. Assessing the relationship between admission glucose levels, subsequent length of hospital stay, readmission and mortality. Clin Med 2012;12:137-9.

54 Cornish W. Safe and appropriate use of insulin and other antihyperglycemic agents in hospital. Can J Diabetes 2014;38:94-100.

55 Inzucchi SE, Bergenstal RM, Buse JB, et al. Management of hyperglycemia in type 2 diabetes, 2015: a patient-centered approach: update to a position statement of the american diabetes association and the European Association for the Study of Diabetes. Diabetes Care 2015:38:140-9.

56 Franco $\mathrm{OH}$, Steyerberg EW, Hu FB, et al. Associations of diabetes mellitus with total life expectancy and life expectancy with and without cardiovascular disease. Arch Intern Med 2007:167:1145-51.

57 Patel A, MacMahon S, Chalmers J, et al., ADVANCE Collaborative Group. Intensive blood glucose control and vascular outcomes in patients with type 2 diabetes. N Engl J Med 2008;358:2560-72. 
58 Gerstein HC, Miller ME, Genuth S, et al., ACCORD Study Group. Long-term effects of intensive glucose lowering on cardiovascular outcomes. $N$ Engl J Med 2011;364:818-28.

59 Duckworth W, Abraira C, Moritz T, et al. Glucose control and vascular complications in veterans with type 2 diabetes. N Engl J Med 2009;360:129-39.

60 Antithrombotic Trialists' Collaboration. Collaborative meta-analysis of randomised trials of antiplatelet therapy for prevention of death, myocardial infarction, and stroke in high risk patients. BMJ 2002:324:71-86.

61 Belch J, MacCuish A, Campbell I, et al. The prevention of progression of arterial disease and diabetes (POPADAD) trial: factorial randomised placebo controlled trial of aspirin and antioxidants in patients with diabetes and asymptomatic peripheral arterial disease. BMJ 2008;337:a1840.

62 Ogawa H, Nakayama M, Morimoto $T$, et al. Low-dose aspirin for primary prevention of atherosclerotic events in patients with type 2 diabetes: a randomized controlled trial. JAMA 2008;300:2134-41.

63 De Berardis G, Sacco M, Evangelista V, et al. Aspirin and simvastatin combination for cardiovascular events prevention trial in diabetes (ACCEPT-D): design of a randomized study of the efficacy of low-dose aspirin in the prevention of cardiovascular events in subjects with diabetes mellitus treated with statins. Trials 2007:8:21.

64 Gupta N, Mansoor S, Sharma A, et al. Diabetic retinopathy and VEGF. Open Ophthalmol J 2013;7:4-10.

65 American Diabetes Association. (9) Microvascular complications and foot care. Diabetes Care 2015;38(Suppl):S58-66.

66 NHS. Foot care for people with diabetes in the NHS in England: The economic case for change. http://www.diabetes.org.uk/upload/News/Factsheet\%20Footcare\%20for \%20people\%20with\%20diabetes.pdf. Updated Mar 2012.

67 [No authors listed]. Effects of ramipril on cardiovascular and microvascular outcomes in people with diabetes mellitus: results of the HOPE study and MICRO-HOPE substudy. Heart Outcomes Prevention Evaluation Study Investigators. Lancet 2000;355:253-9.

68 Knowler WC, Barrett-Connor E, Fowler SE, et al. Reduction in the incidence of type 2 diabetes with lifestyle intervention or metformin. $N$ Engl J Med 2002;346:393-403.

69 Charlton B, Taylor-Edwards C, Tisch R, et al. Prevention of diabetes and insulitis by neonatal intrathymic islet administration in NOD mice. J Autoimmun 1994; 7:549-60.

70 Wherrett DK, Bundy B, Becker DJ, et al. Antigen-based therapy with glutamic acid decarboxylase (GAD) vaccine in patients with recent-onset type 1 diabetes: a randomised double-blind trial. Lancet 2011;378:319-27

71 Voltarelli JC, Couri CE, Stracieri AB, et al. Autologous nonmyeloablative hematopoietic stem cell transplantation in newly diagnosed type 1 diabetes mellitus. JAMA 2007;297:1568-76.

72 Bruni A, Gala-Lopez B, Pepper AR, et al. Islet cell transplantation for the treatment of type 1 diabetes: recent advances and future challenges. Diabetes Metab Syndr Obes 2014;7:211-23.
73 Barton FB, Rickels MR, Alejandro R, et al. Improvement in outcomes of clinical islet transplantation: 1999-2010. Diabetes Care 2012;35:1436-45.

74 Russell SJ, El-Khatib FH, Sinha M, et al. Outpatient glycemic control with a bionic pancreas in type 1 diabetes. N Engl J Med 2014;371:313-25.

75 Hartstra AV, Bouter KE, Bäckhed F, et al. Insights into the role of the microbiome in obesity and type 2 diabetes. Diabetes Care 2015:38:159-65.

\section{Answers}
1. A. True
B. True
C. False (increased)
D. True
E. False (increased)

2. A. True

B. False (withdrawn)

C. True

D. True

E. True

3. A. True

B. False

C. False (weight gain)

D. True

E. False

4. A. True

B. False (type 1)

C. True

D. True

E. False

5. A. True

B. True

C. False

D. True

E. True 